\title{
Selection of Hydrocolloid to formulate processed Tomato salsa with herbs
}

\author{
Aruna Kumari Yadla ${ }^{1}$ and Poonam A Sachdev ${ }^{2}$ \\ ${ }^{1}$ Teaching Associate, Dept. of Food Technology, College of Food Science and Technology, ANGRAU, Bapatla, \\ Andhra Pradesh. India \\ ${ }^{2}$ Professor, Department of Food Science and Technology, Punjab Agricultural University, Ludhiana, Punjab, \\ India
}

\begin{abstract}
The present study was carried out to standardize processed tomato salsa with herbs. Formulation of tomato salsa was finalized on the basis of sensory evaluation as tomato (70\%), vinegar (10\%), sugar (8\%), cilantro (1.5\%), onion (5.2\%), garlic (0.6\%), capsicum (1.5\%), green chilli $(0.6 \%)$, oregano $(0.3 \%)$, cumin $(0.15 \%)$, pepper $(0.15 \%)$, and salt $(2 \%)$. pectin, sodium alginate, CMC (carboxy methyl cellulose) and guar gum were added to processed tomato salsa with different levels of concentrations $(0.2,0.4,0.6,0.8$ and $1.0 \%)$ to avoid separation of serum from product and to improve viscosity. Guar gum at $0.2 \%$ concentration showed high viscosity compared with other hydrocolloids of same concentration, and scored higher in overall acceptability of formulated product.
\end{abstract}

Keywords: Guar gum, tomato salsa, viscosity, overall acceptability, cilantro

\section{Introduction}

The objective of this work is to present and discuss some aspects of formulation of tomato salsa with herbs. In particular the formulation was standardized using fresh and steeped ingredients and the physicochemical and sensory properties of the processed tomato salsa were studied. The main part of the study oriented towards the suitability of hydrocolloid to give proper texture (viscosity) and to gain overall acceptability of the product.

Hydrocolloids are used for a wide range of different functions within food: thickening, gelling, generating mouth-feel, film-forming, foaming, improving bake-stability, improving freeze-thaw stability, preventing crystal growth, stabilizing suspensions or emulsions, and encapsulation. It can therefore be a challenge to select the right hydrocolloid for a specific food end-product.CMC (carboxy-methyl-cellulose) forms clear, viscous solutions (a range of viscosities are available).CMC shows protective colloid properties in acidified milk drinks and also works as thickening and stabilizing agent. Guar gum forms viscous solutions with a long texture and it works only as a thickening agent. Alginates or more specifically sodium alginates can be used as a thickening agent (different grades offer a range of viscosities). Alginates can form strong, cohesive, thermo-resistant gels in the presence of calcium ions and also work as thickening and gelling agent. Low methoxyl pectins also form gels - partly shear reversible and also work only as gelling agent (foodeurope@brenntag.eu).

Guar gum is found in the endosperm of the seeds of the guar plant, Cyamopsis tetragonoloba, which is milled in order to obtain guar gum (Meer1977; Wielinga 2000). Guar gum is a neutral hydrocolloid with linear chains of Dmannopyranosyl units with D-galactopyranose substituents protruding by (1-6) linkages. For every galactose residue there are approximately two mannose residues.

Tomato has an excellent nutritional profile owing largely to its balanced mixture of vitamins such as A, B1, B2, K, biotin, folic acid, nicotinic and pantothenic acids, vitamin-C (160-240 mg/kg), vitamin-E (5-20 $\mathrm{mg} / \mathrm{kg}$ ), and minerals like potassium, calcium, phosphorus, iron and zinc. It is a richest source of antioxidants, lycopene $(60-90 \mathrm{mg} / \mathrm{kg}$ ), phenolic acids (ferulic, chlorogenic, caffeic acids $10-50 \mathrm{mg} / \mathrm{kg}$ ) with immunostimulatory properties (Berry 2007 and Kaur et al 2004). $\beta$-carotene and lycopene contribute 7 and 87 per cent respectively of total carotenoids in ripe and red tomatoes (Singh and Rai 2006).

Tomatoes are consumed as such, canned or processed into tomato ketchup, paste, puree, sauce and chutney (Sethi and Anand 1986). However the wide individual variation in what human beings live on, led to noticeable changes in eating behavior and in certain cases, it has posed substantial demand for new types of food. The new demands include more types of food, less energy dense foods, less fat, less salt and more dietary fibers which leads to preference for so called 'light' foods, products with reduced fat and energy (Sabapathy and Bawa 2007). So there is a need to develop product with low calorie, low fat, high fiber and antioxidant rich ready to serve/use tomato products. Tomato salsa is one such kind of product with low calorie, high fiber, vitamin and mineral rich product. Tomato salsa is described as having firm chunks of whole tomato suspended in an aqueous medium of fresh juice or pulp fully blended with chopped ingredients such as onions, garlic, salt 
and acid (Allison et al 1999). The most desirable qualities for processing of tomatoes have been considered as high total solids $(4.62 \%)$, acidity ( 0.3 to $0.4 \%)$, smooth surface, free from wrinkles, small core, firm flesh and uniform ripening (color) (Sethi and Anand 1986).

Production of salsa will be beneficial to the farmers as well as entrepreneurs because it requires minimum equipment and machinery; and can also be prepared at home scale with low cost. Tomato salsa is a low calorie, shelf stable product from a highly nutritive perishable vegetable (tomato). Addition of herb (cilantro and oregano leaves) will not only increase sensory quality but also enhance nutritional profile of the product with certain vitamins, minerals, antioxidants and antimicrobial agents that these herbs contain naturally (Saha et al 2007).

Schauwecker et al (2000) studied tomato salsa for its sensory evaluation, shelf life and microbial loads of salsa containing microwave dehydrated cilantro (herb). The results given that salsa containing micro wave vacuum dehydration (MIVAC) process (dries heat sensitive food materials at low temp.) treated cilantro was not preferred to salsa containing fresh cilantro added at the same time of processing as the MIVAC - treated product. Because the volatiles contained in the cilantro vaporize at relatively low temperatures. Chambers $1 \mathrm{~V}$ and Aramouni (2000) summarized that honey had little effect on perception of burn in heat processed salsa. Heat processed salsa was rated higher in overall acceptability than fresh salsa, and increasing honey level reduced water activity and moisture in processed and fresh salsas (www.humec.k-state.edu). Allison et al (1999) studied sensory characteristics of salsa. They developed heat processed and fresh Salsa containing honey (up to $10 \%$ ) with different levels of acid and capsaicin. Descriptive sensory characteristics and consumer acceptability of the salsas were studied. Increasing levels of honey increased sweetness and crispness of both salsas. Higher levels of honey decreased oral heat intensity. Consumers liked heat processed salsa better than fresh and acceptability generally decreased with increasing honey content. However about one-third of consumers liked salsas with honey more than samples with out honey. Based on the reviews available and sensory scores of trained and semi trained panelists tomato salsa was standardized.

\section{Materials and methods}

Raw materials (onion, garlic, Green chillies, capsicum, cilantro and oregano leaves) were thoroughly cleaned with soft water. Tomatoes were blanched and peeled and cut into halves to remove core and seeds. Then these materials were chopped into small cubes with a food processor chopping machine. Tomato puree was prepared by concentrating tomato juice up to 8.37 per cent TSS. Steeped ingredients were prepared using $2 \%$ brine, where onion, garlic, cilantro, mint, capsicum, chillies and chives were steeped in glass jars. Later mint and chives were discarded due to their incompatibility with the processed tomato salsa.

Tomato salsa was prepared by mixing all ingredients such as tomato slices, tomato puree, onion, garlic, green chillies, capsicum, cilantro, salt, sugar, vinegar, oregano leaves, pepper and cumin powder in a frying pan and was heated, followed addition of pectin, sodium alginate, CMC (carboxy methyl cellulose) and guar gum were added to processed tomato salsa with different levels of concentrations $(0.2,0.4,0.6,0.8$ and $1.0 \%)$ individually and simmered for 30 minutes and filled hot into glass jars then sealed and processed at $100^{\circ} \mathrm{C}$ for 30 minutes in boiling water to ensure heat processing and were stored at refrigeration temperatures $\left(4-10{ }^{\circ} \mathrm{C}\right)$.

Physico-chemical analysis of samples of processed tomato salsa formulations, which were formed with fresh and steeped ingredients were carried out for various physico chemical characteristics including moisture, total soluble solids, total and reducing sugars, $\mathrm{pH}$, acidity, ascorbic acid, lycopene and viscosity by the methods followed from Ranganna (1986). Tomato salsa formulations with different hydrocolloids were analyzed for sensory and viscosity. Product viscosity was calculated by using Brookfield viscometer (Ranganna, 1986). APHA (1984) method was used for microbial count and sensory evaluation by nine point hedonic scale.

The data regarding moisture, total soluble solids, total and reducing sugars, $\mathrm{pH}$, acidity, ascorbic acid, carotene, lycopene, viscosity, tannins, total phenolics, flavonoids of all samples at one month interval were statistically analyzed to find out the effect of packaging material and storage period on the product with the help of factorial design in CRD using the software CPCS-1(Singh, 1991). Each value was recorded mean of three observations.

Viscosity of tomato salsa was measured by Brookfield viscometer. The viscosity of the samples containing various hydrocolloids was determined. The spindle used for measurement was 3 and the speed was $60 \mathrm{rpm}$ (revolutions per minute). Temperature of all the samples was maintained at $20^{\circ} \mathrm{C}$.

\section{Results and Discussion}

Recipe was standardized according to sensory scores of the product (Table 1) prepared with different levels of vinegar, sugar, salt and herbs (cilantro, oregano leaves). Tomato salsa with steeped ingredients (onion, garlic, cilantro and capsicum) also showed good response from the panelists (Table 2). Prepared recipe of tomato salsa was Standardized following the research done by Allison et al (1999) and Carlsen et al (1997). 
Table 1: Standardization of formulation of tomato salsa $(n=10)$

\begin{tabular}{|c|c|c|c|c|}
\hline \multirow{2}{*}{$\begin{array}{l}\text { Level (\%) } \\
\text { Parameter }\end{array}$} & \multicolumn{4}{|c|}{ Sensory parameter } \\
\hline & Appearance & Flavor & Consistency & Overall acceptability \\
\hline \multicolumn{5}{|l|}{ Vinegar (\%) } \\
\hline 8 & 7.5 & 7.5 & 8.0 & 7.7 \\
\hline $10^{*}$ & 8.5 & 8.5 & 7.5 & 8.2 \\
\hline 12 & 7.5 & 8.0 & 7.5 & 7.7 \\
\hline 15 & 8.5 & 7.5 & 7.0 & 7.7 \\
\hline \multicolumn{5}{|l|}{ Sugar $(\%)$} \\
\hline $8^{*}$ & 8.0 & 8.5 & 7.5 & 8.0 \\
\hline 10 & 7.5 & 8.0 & 7.0 & 7.5 \\
\hline 12 & 7.5 & 8.0 & 7.0 & 7.5 \\
\hline 15 & 7.0 & 8.0 & 8.5 & 7.8 \\
\hline LSD (P $\leq 0.05)$ & 1.1 & 0.2 & 0.7 & 0.5 \\
\hline \multicolumn{5}{|l|}{ Cilantro (\%) } \\
\hline 1.0 & 7.5 & 8.0 & 8.0 & 7.7 \\
\hline $1.5^{*}$ & 8.0 & 8.5 & 8.5 & 8.2 \\
\hline 2.0 & 8.0 & 7.5 & 7.5 & 7.7 \\
\hline LSD (P $\leq 0.05)$ & 1.6 & 1.9 & 1.3 & 1.5 \\
\hline
\end{tabular}

(*:-Selected level for the recipe, LSD: Least Significant Difference)

The data regarding the effect of different levels of acetic acid, sugar and cilantro concentrations on organoleptic quality of tomato salsa have been represented in Table 1. In tomato salsa, vinegar, sugar and cilantro were tried in different levels: vinegar and sugar were used at 8,10,12 and $15 \%$ levels and Cilantro was used in 1.0, 1.5 and $2.0 \%$ level. Sugar and acid levels were finalized to 8 and 10 per cent, according to sensory parameters tested by semi trained and trained panelists. Above $15 \%$ level of vinegar and sugar in salsa gave more sweet and sour taste like tomato ketchup and the heat sensitiveness of the product covered by high level of sugar and acid concentration where as below $8 \%$ level gave bland taste and appearance (colour) scores were decreased with increase in the concentration of the sugar. Cilantro at $1.5 \%$ level was scored high for flavor and at $2 \%$ level product showed dominant flavor. As sugar, acid have effect on hydrocolloid suitability, so as to maintain $\mathrm{pH}$ levels suitable for good viscosity of the product these were standardized initially.

According to Carlsen et al (1997), microwave/vacuum dehydrated cilantro was added at the level of 0.5 $\%$ for processed tomato salsa which was selected by the sensory evaluation. According to Allison et al (1999) increased acidity suppressed the sweet perception in heat processed salsa. There was significant difference in sensory scores of the tomato salsa prepared with various levels of vinegar, sugar and cilantro.

Kim et al (2006) stated that the sensitivity to the anti yeast activity of heated garlic or heated allicin (component of garlic) was quite different depending on the yeast strain. Species belonging Zygosaccharomyces were the least sensitive, while Candida utilis and Pichia membranaefaciens were among the most sensitive.

Schauwecker et al (2000) reported that no microbial growth was observed for processed tomato salsa during initial observations and after storage for one year. The hot-fill-hold method applied to produce the salsa was an effective method to eliminate viable microbial loads.

Azizi et al (2009) reported that carvacrol was the dominant compound (70.0-77.4\%) for all essential oil samples of oregano (Origanum vulgare L.) leaves, followed by $\gamma$-terpinene (8.1-9.5 \%) and p-cymene (4.5$5.3 \%$ ). Carvocrol and thymol (major components of oregano) particularly when used in combination with a stabilizer or in an ethanol solution, may be effective in reducing the number or preventing growth of Escherichia coli O157:H7 in liquid foods (Burt et al 2005).

\subsection{Physico-chemical and sensory evaluation of tomato salsa prepared with Fresh and Steeped ingredients}

Standardized recipe of tomato salsa prepared with fresh and steeped ingredients was evaluated physico chemically and organoleptically (Table 2). Sensory scores of tomato salsa with fresh ingredients were higher than tomato salsa with steeped ingredients, there were lower flavor scores (8.16) in tomato salsa with steeped ingredients than tomato salsa containing fresh ingredients (8.5). Overall acceptability scores of tomato salsa containing fresh ingredients were significantly $(\mathrm{P}>0.5)$ higher than salsa containing steeped ingredients. There was significant difference in $\mathrm{pH}$, acidity, ascorbic acid and total sugars where as non significant difference was found in moisture, TSS, reducing sugars and lycopene of the tomato salsa with fresh and steeped ingredients. So tomato salsa with fresh ingredients was selected further for analysis of storage stability. 
Table 2: Physico-chemical and sensory evaluation of tomato salsa prepared by fresh and steeped

\begin{tabular}{|c|c|c|c|}
\hline Parameter & Fresh & Steeped & LSD (P $\leq 0.05)$ \\
\hline Moisture (\%) & 84.0 & 83.7 & $\mathrm{NS}$ \\
\hline $\operatorname{TSS}\left({ }^{\circ} \mathrm{B}\right)$ & 14.0 & 15.5 & NS \\
\hline Acidity (\% A.A) & 0.4 & 0.8 & 0.12 \\
\hline $\mathrm{pH}$ & 4.0 & 2.8 & 1.20 \\
\hline Ascorbic acid (mg/100g) & 6.8 & 3.1 & 0.09 \\
\hline Lycopene (mg/100g) & 9.9 & 7.4 & NS \\
\hline Reducing sugars (\%) & 5.2 & 4.0 & NS \\
\hline Total sugars $(\%)$ & 6.0 & 12.4 & 2.16 \\
\hline Appearance $(n=10)$ & 8.5 & 7.8 & 0.11 \\
\hline Flavour $(\mathrm{n}=10)$ & 8.5 & 8.2 & 0.13 \\
\hline Consistency $(n=10)$ & 7.7 & 7.5 & 0.07 \\
\hline Overall acceptability $(n=10)$ & 8.2 & 7.8 & 0.06 \\
\hline
\end{tabular}

\subsection{Selection and standardization of levels of hydrocolloid}

Effect of various hydrocolloids and their different levels on the viscosity and sensory quality of the tomato salsa is shown in Table 3. Fresh (unprocessed) salsa showed extensive separation of serum from the product but hydrocolloid had no effect on consistency and separation of serum of fresh (unprocessed) salsa as the reason noted that the gelation of hydrocolloid occurs when it is heated. So pectin, sodium alginate, CMC (carboxy methyl cellulose) and guar gum were added to processed tomato salsa with different levels of concentrations $(0.2,0.4,0.6,0.8$ and $1.0 \%)$ to avoid separation of serum from product. Organoleptic evaluation of tomato salsa with various hydrocolloids differed in levels showed significant difference in their appearance, flavor and taste, texture and consistency, overall acceptability and viscosity. Guar gum has improved the flavoring characteristics of the product when compared with other hydrocolloids so guar gum with minimum quantity $(0.2 \%)$ was selected for the product.

The consistency of tomato salsa containing $0.2 \%$ guar gum was optimum which showed $1640 \mathrm{cPs}$ resulting in higher scores of appearance (8.5), flavor (8.5), consistency (8.5) and overall acceptability (8.5) for the product. Phillips et al (1984) reported that guar gum showed good compatibility with the soup in terms of flavor, taste and consistency as it improved the overall mouth feel of the soup and it enabled a rounding of the different flavoring components in the soup.

Table 3: Effect of various hydrocolloids on the viscosity and sensory parameters of the tomato Salsa $(n=10)$

\begin{tabular}{|c|c|c|c|c|c|c|}
\hline \multirow{2}{*}{ Hydrocolloid } & \multirow{2}{*}{$\begin{array}{c}\text { Level } \\
(\%)\end{array}$} & \multicolumn{4}{|c|}{ Sensory parameters } & \multirow[b]{2}{*}{$\begin{array}{l}\text { Viscosity } \\
\text { (cPs) }\end{array}$} \\
\hline & & $\begin{array}{c}\text { Appearanc } \\
\text { e }\end{array}$ & $\begin{array}{c}\text { Flavou } \\
\mathbf{r}\end{array}$ & $\begin{array}{c}\text { Texture } \\
\text { \&consistency }\end{array}$ & $\begin{array}{c}\text { Overall } \\
\text { acceptability }\end{array}$ & \\
\hline \multirow{5}{*}{ Pectin } & 0.2 & 7.0 & 7.0 & 7.0 & 7.0 & 560 \\
\hline & 0.4 & 8.0 & 8.0 & 8.0 & 8.0 & 845 \\
\hline & 0.6 & 7.5 & 7.5 & 7.7 & 7.6 & 650 \\
\hline & 0.8 & 7.0 & 7.0 & 7.0 & 7.0 & 945 \\
\hline & 1.0 & 8.0 & 8.0 & 8.0 & 8.0 & 1180 \\
\hline \multirow{5}{*}{$\begin{array}{l}\text { CMC (carboxy methyl } \\
\text { cellulose) }\end{array}$} & 0.2 & 6.5 & 7.0 & 7.5 & 7.0 & 840 \\
\hline & 0.4 & 7.0 & 7.0 & 7.0 & 7.0 & 1450 \\
\hline & 0.6 & 8.0 & 8.0 & 8.0 & 8.0 & 1580 \\
\hline & 0.8 & 6.5 & 8 & 7.5 & 7.6 & 1740 \\
\hline & 1.0 & 8.0 & 8.0 & 8.0 & 8.0 & 1780 \\
\hline \multirow{5}{*}{ Sodium alginate } & 0.2 & 7.5 & 7.6 & 7.6 & 7.6 & 980 \\
\hline & 0.4 & 7.5 & 8.0 & 8.0 & 8.0 & 1100 \\
\hline & 0.6 & 8.0 & 8.0 & 8.0 & 8.0 & 1240 \\
\hline & 0.8 & 8.5 & 7.0 & 8.0 & 7.5 & 1580 \\
\hline & 1.0 & 8.5 & 7.5 & 8.0 & 8.0 & 1700 \\
\hline \multirow{5}{*}{ Guar gum } & 0.2 & 8.5 & 8.5 & 8.5 & 8.5 & 1640 \\
\hline & 0.4 & 8.0 & 8.0 & 8.5 & 8.2 & 1700 \\
\hline & 0.6 & 8.0 & 8.7 & 8.0 & 8.2 & 1740 \\
\hline & 0.8 & 8.0 & 8.5 & 8.6 & 8.4 & 1815 \\
\hline & 1.0 & 7.5 & 8.5 & 8.0 & 8.0 & 1840 \\
\hline $\operatorname{LSD}(\mathrm{P} \leq .05)$ & - & 0.5 & 0.5 & 0.5 & 0.6 & 1.7 \\
\hline
\end{tabular}




\section{Summary}

It was concluded that fresh ingredients were suitable for preparation of tomato salsa. Guar gum at $0.2 \%$ level was optimum to improve viscosity and to avoid separation of water from product. Formulation of tomato salsa was finalized on the basis of sensory evaluation and the selected levels of vinegar, sugar and cilantro were found to be $10 \%, 8 \%$ and $1.5 \%$ respectively in $70 \%$ of tomato which was the major ingredient of tomato salsa. The remaining ingredients i.e. onion $(5.2 \%)$, garlic $(0.6 \%)$, capsicum $(1.5 \%)$, green chilli $(0.6 \%)$, oregano $(0.3 \%)$, cumin $(0.15 \%)$, pepper $(0.15 \%)$ and salt $(2 \%)$ were added according to the taste and acceptability of the panelists. Four hydrocolloids i.e. Carboxy methyl cellulose (CMC), guar gum, pectin and sodium alginate were added to the tomato salsa at different concentrations $(0.2,0.4,0.6,0.8$ and $1 \%)$ to avoid the separation of serum from the product. Out of four hydrocolloids guar gum at $0.2 \%$ was found optimum on the basis of consistency and sensory evaluation. Microbial analysis found negligible plate count of bacteria and fungi $(<20$ and $<35$ respectively) in formulated tomato salsa with herbs.

\section{References}

[1]. Allison A A, Chambers IV E, Gibson E and Aramouni F M (1999) Sensory characteristics of Heat processed and fresh tomato salsa containing Honey. J Fd Sci 64 : 560-64.

[2]. Anonymous (1984) Method of microbiological examination of food. (APHA) American Public Health Association, Washington.

[3]. Azizi A, Yam F and Honermeoer B (2009) Herbage yield, essential oil content and composition of three oregano (Oreganum vulgare L.) populations as affected by soil moisture regimes and nitrogen supply. Industrial crops and products 29:554-561

[4]. Berry S K (2007) Healthier living the tomato way. J Processed Food Industry 10: 21-28.

[5]. Burt S A,Vlielander R, Haagsman H P and Veldhuizen E J A (2005) Icreased activity of essential oil components carvocrol and thymol against Escherichia coli O157:H7 by addition of food stabilizers. J. of Food Protection 68:919-926. Kaur B and Bains G S (1992) Comparative studies on 'Ready to serve' canned okra/lady's fingers (Hibiscus esculentus L.) in brine and tomato juice. Indian Fd Packer 46: 21-26

[6]. Carlsen K, Duran E, Landa J and Ferris D A (1997) A new tomato based salsa CATI Research Publications (CFSNR), California.

[7]. Kaur C, George B, Deepa N, Singh B and Kapoor H C (2004) Antioxidant Status of fresh and processed tomato. J Fd Sci Technol 41: 479-86

[8]. Kim Y S, Choi J H and Kyung K H (2006) Anti yeast potency of heated garlic in relation to the content of allyl alcohol thermally generated from allin. J Fd Sci 71:185-189.

[9]. Meer, W. (1977). Plant Hydrocolloids. Food Colloids. H. Graham. Westport, AVI Publishing: 522-539.

[10]. Ranganna S (1986) Handbook of analysis and quality controle for fruit and vegetable products (second edition). Tata Mc-Graw Hill Publishing company Ltd. New Delhi. Pp1112, 514.

[11]. Sabapathy S N and Bawa A S (2007) Nutritional assessment of industrially processed foods. The Ind J Nutr Dietet $44: 89-95$

[12]. Saha B, Maity T K and Mishra A K (2007) Herbs and spice-naturally occurring antimicrobials. The Ind J Nutr Dietet 44:89-95.

[13]. Schauwecker A, Ochoa H and Ferris D A (2000) A New Tomato based Salsa : Continued Sensory evaluation and shelf life studies of the microbial loads of salsa containing. Microwavedehydrated cilantro. CATI Research Publications (CFSNR), California.

[14]. Sethi V and Anand J C (1986) Quality characteristics of hybrid tomatoes for puree preparation. Indian Fd Packer 40: 13-19.

[15]. Singh J and Rai M (2006) Lycopene in tomato for Human Health. J Indian Hort 54 : 33-34.

[16]. Singh S, Singh T, Bansal M L and Kumar R (1991) Statistical methods for research workers. Kalyani Publishers, New Delhi.

[17]. Wielinga, A. M. (2000). Galactomannans. Handbook of Hydrocolloids. P. W. GO Phillips. Boca Raton, CRC Press: $137-154$.

[18]. http://www.humec.k-state. edu

[19]. http://www.food-europe@brenntag.eu 